\title{
HARDWARE DEVELOPMENT AND GROUND-BASED STUDIES FOR DROP SHAFT EXPERIMENT ON OSCILLATORY CONVECTION IN HALF FLOATING ZONE
}

\author{
Y. L. Yao, J. Z. Shu, J. C. Xie, Z. M. Tang, F. Liu, R. Zhou and \\ W. R. Hu \\ Institute of Mechanics, Chinese Academy of Sciences, Beijing 100080, China
}

\begin{abstract}
Coordinated measurement of ternperature, velocity and free surface oscillation were obtained by using the drop shaft facility for microgravity experiments of half fluating zone convection. The ground-based sludies gave transition from steady to uscillatory convection for multi-quantities measurement.
\end{abstract}

\section{INTRODUCTION}

Experiments of thermocapillary convection in half floating zone have been mostly performed on the ground since $1975 / 1-7 /$. Experiments were also completed on board the microgravity sounding rocket /8-10/ and space laboratory /11-13/. Only a few of experiment was there to study the steady thermocapillary convection by using the orop tower due to the short experimental period /14/. A quantitative design on drop shaft experiment of oscillatory thermocapillary convection in half floating zone is a challenge subject, and such an experiment was completed by collaborated with the Waseda University of Japan. The hardware development and ground-based studies was summarized in present paper.

The process of onset oscillation is usually described in most cases by the temperature measurement, or recently by the free surface variation. Coordinated measurements of multi-quantities in earth's gravity condition were given in this paper to study the onset of oscillation. The results show that, uscillation may be started at different moment for different quantity.

\section{EXPERIMENTAL HARDWARE}

Diagnostic system is required to measure more physical quantities. The radii variation for me-cross section of liquid bridge was obtained by micro-video system /6/. Two-dimensional free surface variation was measured by method of grid mash (see, for example, $17 /$ ). The coordinated measurennent system of the present experiments was deveioped to integrate the micro-video and grid mash together with the temperature and flow pattern system. Two thermocouples passed through two small holes of 0.25 in diameter at distance $0.85 \mathrm{~mm}$ from the edge of lower rod were used to measure the temperature in the liquid bridge, and tracer parlicle method was used to show the flow pattern. Quantities were measured and recorded in the real time, and the system of measurements was shown in Fig. 1.

The drop capsule is divided into three levels. Four systems of half floating zone and 12 sets of CCD cameras were packed in bottorn level of capsule. The record system included the monitors and 12 sets of VTRs were fixed in the rniddle level, and the electric system and computer were integratred in the upper level. The rod diameter $d_{0}$ of liquid bridge is $3 \mathrm{~mm}$ for two liquid bridges and $4 \mathrm{~mm}$ for other two liquid bridges. The geometric aspext and the volume of liquid bridge, which is described by radii ratio $d_{-} / d_{0}$, are adopted typically. The experiments of fat liquid bridge were also cornpleted. 
The mechenical system of experintental fecility was designed carefully to permit the adjustment of the temperatures, liquid bridge volume and the heigth of rod gap before the drop as shown in Fig. 2. Function of adjustment is great useful for the operation of experiments, especially for the cases of higher applied temperature difference or/and larger llipuid bridge volume, which cases are difficult to be persisted.

\section{GROUND-BASED EXPERIMENT}

From the view point of fluid mechanics, the transition process is associated with the oscillations of velocity, surface wave and quantities of thermophysics. It will be interesting to study experimentally the relationship of all cscillatory features of half floating zone convection in the same time.

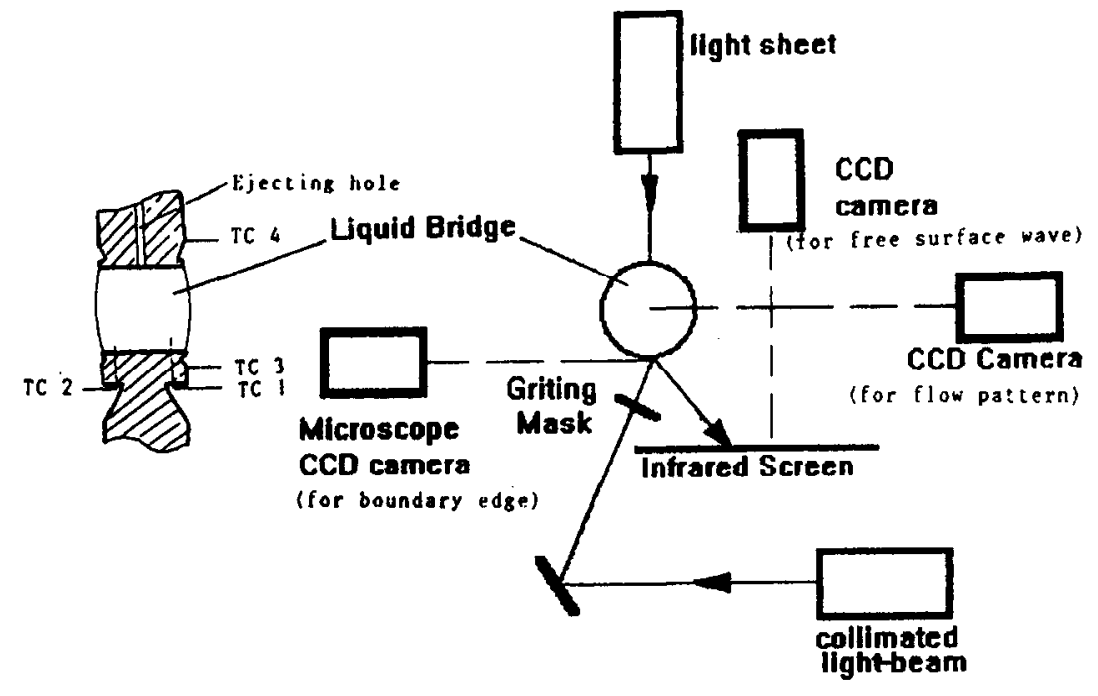

Fig. 1 The system of coordinated measurement for ternperature (left), flow pattern, boundary edge and free surface wave ( $r$ ight) in half floating zone

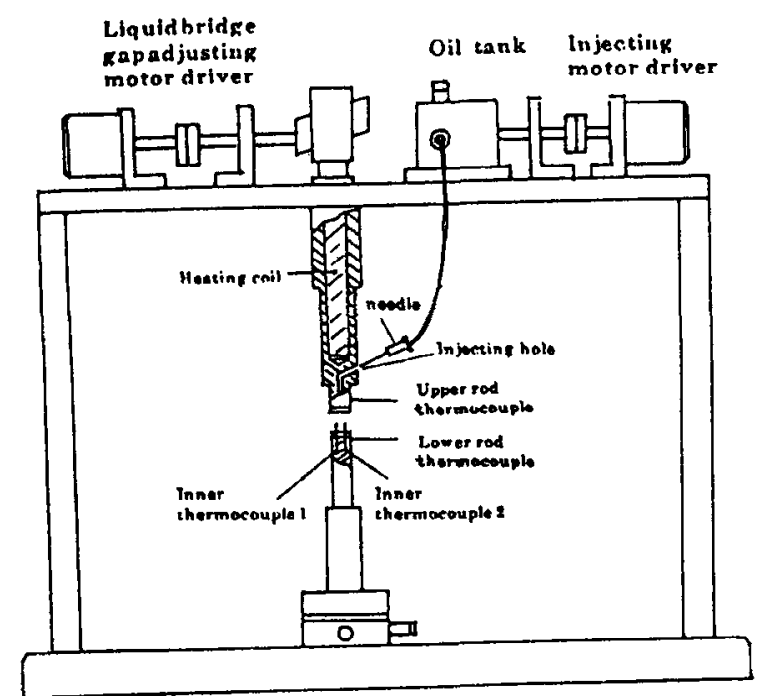

Fis. 2 The schematic diagram of mechanical systern of half floating zone. 
10 cst silican oil was used as the experimental medium. The onset of oscillation may be described by one of the physical quantity, for example, in most cases, temperature measured by thermocouples. However, the oscillation could be also measured by other quantities, such as the velocity at a fixed point or the radii variation of free surface boundary. It will be interesting to give rnore physical quantities, which could be measured to show the uscillatory features, and then to study the onset of oscillation by the coordinated analyses of quantities. The diagnostic systems of present paper as shown in Fig.1 gave the measurernent data of multi-quantities.

The process near the onset of oscillation was obtained by the distributions of temperature in the liquid bridge and the variation of free surface edge in distance $2.1 \mathrm{~mm}$ above the lower rod for $d_{0}=4 \mathrm{~mm}$. The processes of onset of oscillation were obtained for different geometrical aspects and volumes of liguid bridge, which are described by the radii ratio $d_{0} / d_{0}$. A typical process on the onset of oscillation was given in Fig. 3 for boundary edge evolution (upper) and temperature evolution (lower) with a very slow heating rate, which may be controlled as low as $1^{\circ} \mathrm{C}$ per minute. The results of Fig. 3 show that, the onset of oscillation for free surface edge is started obviously early than the one for temperature for the slender liquid bridge. Systematic studies show that, the time difference of onset moments for these two quantities depends on the volume of liquid bridge, and will be discusseed in detail elsewhere. The onset of oscillation for temperatures at position A and B were nearly the same moment. It should be pointed thath time response is less than 0.1 secomid for
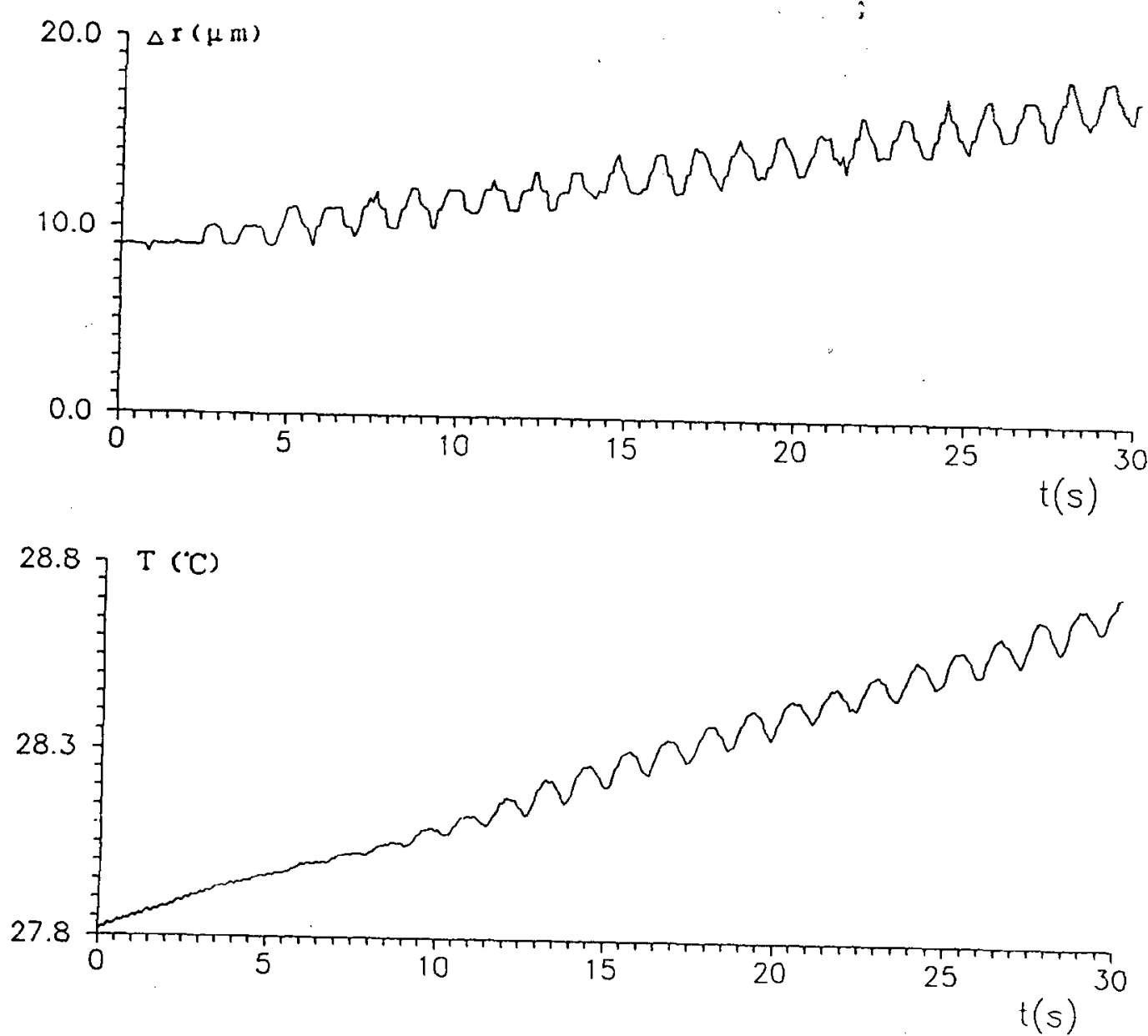

Fig. 3 The starting procisss of onset of oxcillation for boundary edge of free surface (upper) and temperature inside liquid bridge (lower), where $d_{0}=4 \mathrm{~mm}$, A $=0.8^{\prime}$ and $d_{m} / d_{0}=0.7$. 
ternperature measurement by thermocouple and more short for boundary edge measurement, the typical period of ascillation is 1 second in order of magnitude. Therefore, the time delay on onset of oxillation may be several perioxi and is a physical phenomena, but not cornes from measurement errors.

\section{CONCLUSION}

The hardware of ha!f floating zone experiment was development for cquantitative mieasurements of multi-quanlities, such as the free surface variations, the temperature profiles al two points inside the liquid bridge, and the flow pattern. The inulti-quantity measurements in the same time are great important for understanding the intrinsic role of onset of oscillation in thermocapillary convection of half floating zone. Both ground baserd experirnent and microgravity experiment of drop shaft show the high quality of the facility for quantitative experiment and the convenient control by tele-operation.

In comparing the transition process of temperature and free surface vabrition, it seerns that the onsel. uscillation of temperature inside the slender liquid bridge is relatively slow, and there are different features of temperature usillation and the free surface oscillation near the onset of oscillation. This mean that, different physical quantily may has different resiporse in the Iransition processs for thermocapilary convection and the onset of osciliation depend sensitive on the volume of liquid bridge, although the non-uniformity of lemperature at the free surface is great important for driven thermocapillary convection. It will be benefit in the next step to study quantities, which are active in exciting the oscillation.

AKNOWLEDGE Authors aknowledge the helpful discussions with Professor A. Hirata, Dr. S.l. Nishizawa and M. Sakurai of Waseda University in Japan.

\section{REFERENCES}

1. C.E. Chang, W.R. Wilcox, I Crystal Growth, 28, 8 (1975)

2. C..H. Chun, W. Wuest, Acta Astronautica, 5, 681 (1978)

3. F. Preisser, D. Schwabe, A Scharmann, J. Fluid Mecthanics, 126, 545 (1983)

4. Y. Kamotani, S. Ostrach, M. Vargas, J. Crystal Growth, 66, 83 (1984)

5. Z.H. Cao, J.C. Xie, Z.M., Tang, W.R. Hu, Advance in Space Res., 11(7), 166 (1991)

6. W.R. Hu, H.T. You, Z.H. C.o, Sxience in China, A35, 1001 (1992)

7. J.Z. Snu, Y.L. Yao, W.R. Hu, Science in China, A36, 326 (1993)

8. R. Monti, 5th European Symposium on Materials Science under Microgravity, ESA SP-222, 1985

9. D. Schwabe, A. Scharmann, Advance in Space Res., 4, 43 (1984)

10. A. Hirala, S.l. Nishizawa, N. Imaishi, S.I. Yoda, T. Näkamura, A. Kawasaki, International Symposium on Microgravity Science and Application, Beijing, China, May 10-13, 1993

11. L.G. Napolitano, Natur wissenschaften, 73, 352 (1986)

12 Ch.-H. Chun, 7. Siekmann, Research Program of Gerınan Spacelab Mission D-2, Edit. P.R. Sahm, M.H. Keller, B. Schiewe, DARA (1993) 274

13 R. Monti, A. Viviani, L. Carotenuto, Research Program of German Spacelab Mission D-2, DARA (1993) 283

14. S. Ostrach, A. Prauthan, AlAA J. 16, 419 (1978)

15. W.R. Hu, J.Z. Shu, R. Zhou, J. Crystal Growth, (1994), in printing

16. Z.M. Tang, W.R. Hu, 3. Crystal Growth, (1994), in printing 